\title{
Role of artesunate in TGF- $\beta 1$-induced renal tubular epithelial-mesenchymal transdifferentiation in NRK-52E cells
}

\author{
YAQIAN ZHANG ${ }^{1,2^{*}}$, HUANHUAN LI $^{1,2^{*}}$, JIAJUN ZHU $^{3 *}$, TIANTIAN WEI ${ }^{1,2^{*}}$, \\ YINGXIAN PENG ${ }^{1,2}, \mathrm{RAN} \mathrm{LI}^{1,2}$, RUI XU${ }^{4}, \mathrm{MEI} \mathrm{LI}^{1}$ and ANZHOU XIA ${ }^{1}$ \\ ${ }^{1}$ Jiangsu Key Laboratory of New Drug Research and Clinical Pharmacy; ${ }^{2}$ Department of Postgraduate Academy, \\ Xuzhou Medical University, Xuzhou, Jiangsu 221004; ${ }^{3}$ Department of Anesthesiology, \\ Guanyun County People's Hospital, Lianyungang, Jiangsu 222200; ${ }^{4}$ Department of Pharmacy, \\ Suining County People's Hospital, Xuzhou, Jiangsu 221200, P.R. China
}

Received March 11, 2017; Accepted August 21, 2017

DOI: $10.3892 / \mathrm{mmr} .2017 .7728$

\begin{abstract}
The implications of epithelial-mesenchymal transdifferentiation (EMT) have extended beyond the confines of renal fibrosis to renal tubulointerstitial fibrosis. It has been proposed that EMT may be one of the mechanisms involved in the pathogenesis of renal fibrosis. However, the underlying mechanisms remain unknown. Transforming growth factor (TGF)- $\beta 1$ is considered to be an important cytokine which regulates the transdifferentiation of tubular epithelial cells into myofibroblasts in renal tubulointerstitial fibrosis. In the present study, normal rat kidney tubular epithelial cells (NRK-52E) were treated for $48 \mathrm{~h}$ with TGF- $\beta 1(5 \mathrm{ng} / \mathrm{ml})$ and different concentrations of artesunate (ART; 0.01, 0.1 and $1 \mu \mathrm{g} / \mathrm{ml}$ ). Western blotting, reverse transcription-semi quantitative polymerase chain reaction analysis and immunofluorescence staining were used to evaluate the expression of bone morphogenetic protein (BMP)-7, uterine sensitization-associated gene (USAG)-1, E-cadherin, $\alpha$-smooth muscle actin $(\alpha-$ SMA) and extracellular matrix collagen type I (Col I) mRNA. ART was able to attenuate renal injury in a unilateral ureteral obstruction model. However, its anti-fibrotic effect remains to be elucidated. In the present study, it was observed that ART was able to ameliorate the TGF- $\beta 1$-induced alterations in cellular morphology. In addition, ART inhibited the TGF- $\beta 1$-induced USAG-1 increase and the decrease in BMP-7. Treatment with ART markedly attenuated the TGF- $\beta 1$-induced
\end{abstract}

Correspondence to: Professor Anzhou Xia, Jiangsu Key Laboratory of New Drug Research and Clinical Pharmacy, Xuzhou Medical University, 209 Tongshan Road, Xuzhou, Jiangsu 221004, P.R. China

E-mail: 534163783@qq.com

*Contributed equally

Key words: artesunate, bone morphogenetic protein-7, epithelial-mesenchymal transition, renal fibrosis, transforming growth factor- $\beta 1$, uterine sensitization-associated gene 1 upregulation of $\alpha$-SMA and downregulation of E-cadherin. Additionally, ART was able to significantly attenuate the deposition of interstitial collagens, including Col I. The results of the present study further verified the therapeutic efficacy of ART in TGF- $\beta 1$-induced renal interstitial fibrosis. These findings indicated that ART may hold the potential to prevent chronic kidney diseases via the suppression of USAG-1 expression or by increasing BMP-7 expression.

\section{Introduction}

Renal tubulointerstitial fibrosis is a prominent pathological characteristic of chronic kidney disease, and is characterized by extensive interstitial myofibroblast activation and excessive matrix protein accumulation, which are the common attributes of numerous types of chronic kidney disease leading to end-stage renal disease $(1,2)$. Previous studies have demonstrated that transforming growth factor (TGF)- $\beta 1$ serves an important role in mediating chronic inflammation, myofibroblast activation and extracellular matrix (ECM) accumulation (3-5). At present, there are no effective treatments for renal interstitial fibrosis or ways to impede the progress of the associated chronic kidney disease. Therefore, it is of importance to investigate potential strategies to prevent the development of renal interstitial fibrosis in the diseased kidneys.

Although studies have focused on renal interstitial fibrosis, the mechanism underlying its prevalence remains to be elucidated. Among the putative mechanisms, epithelial-mesenchymal transition (EMT) has become a popular hypothesis (6). The primary events of EMT include the adoption of a mesenchymal-like cellular phenotype and migration through the tubular basement membrane towards the tubular interstitium. It has been established that a number of factors are involved in the process of EMT, which include the profibrotic factor TGF- $\beta 1$ and the antifibrotic cytokine bone morphogenetic protein-7 (BMP-7). These are the important molecules that determine the fate of the kidney as they hold the potential to initiate and complete the process of EMT $(7,8)$.

It was previously demonstrated that the product of uterine sensitization-associated gene 1 (USAG-1) acts as a 
kidney-specific BMP antagonist, which binds to and inhibits the biological activity of BMP-7 (9-14). A previous study revealed USAG-1-deficient mice to be resistant to in vivo kidney injury, while genetic ablation of USAG-1 in the chronic renal injury model of unilateral uretral obstruction (UUO) resisted kidney injury and therefore prolonged survival (15). However, following administration of USAG-1 ${ }^{-/}$mouse anti-BMP-7 neutralizing antibody, the $\mathrm{USAG}^{-/-}$renal protective effect in mice was inhibited. Since USAG-1 may serve a notable role in the regulation of BMP-7 renal protection, inhibiting USAG-1 expression may represent a promising therapeutic measure for the treatment or management of renal interstitial fibrosis.

Artemisinin, extracted and isolated from Artemisia annua compositae leaves, is a sesquiterpene compound with a peroxide bridge. In addition to exhibiting anti-malarial effects, artemisinin has anti-inflammatory, anti-tumor and anti-fibrotic effects $(16,17)$. Artesunate (ART) is an artemisinin derivative, and has been demonstrated to exhibit a therapeutic effect in the treatment of pulmonary fibrosis, liver fibrosis and myocardial fibrosis $(18,19)$. Additionally, a previous study confirmed that ART was able to effectively alleviate renal fibrosis caused by UUO (20); however, whether ART inhibits the occurrence of EMT by inhibiting the activity of USAG-1 or activating the activity of BMP-7 remains unclear.

In the present study, the effect of ART on TGF- $\beta 1$-induced EMT was investigated with the aim of examining the potential underlying mechanism. The mechanism may be used to elucidate the association between the effect of ART and the abnormal expression of BMP-7 and USAG-1.

\section{Materials and methods}

Reagents. Dulbecco's modified Eagle's medium (DMEM)/high glucose was purchased from Gibco ${ }^{\circledR}$ (Thermo Fisher Scientific, Inc., Waltham, MA, USA), Ausbian fetal bovine serum (FBS) was purchased from Thermo Fisher Scientific, Inc. and penicillin-streptomycin solution was purchased from Beyotime Institute of Biotechnology (Haimen, China). Trypsin/EDTA solution was purchased from Beijing Solarbio Science and Technology Co., Ltd. (Beijing, China) and the semi-quantitative polymerase chain reaction (sq-PCR) kit was obtained from Tiangen Biotech Co., Ltd. (Beijing, China). For western blotting, BMP-7 (cat. no. ab56023), USAG-1 (cat no. ab99340), E-cadherin (cat. no. 5409-1) and $\alpha$-smooth muscle actin ( $\alpha$-SMA) (cat. no. 1184-1) antibodies were all purchased from Abcam (Cambridge, UK), GAPDH antibody was obtained from Zhongshan Jinqiao Biotechnology Co., Ltd. (Beijing, China), and for immunofluorescence staining, USAG-1 (cat. no. sc-162253) antibody was obtained from Santa Cruz Biotechnology, Inc. (Dallas, TX, USA), the secondary antibodies were from Zhongshan Jinqiao Biotechnology Co., Ltd. (Beijing, China).

Cell culture and treatment. Normal rat kidney tubular epithelial cells (NRK-52E) were purchased from the Chinese Academy of Sciences Cell Bank (Shanghai, China) and maintained in DMEM/high-glucose medium supplemented with $1 \%$ penicillin-streptomycin and $10 \% \mathrm{FBS}$, in a humidified incubator containing $95 \%$ air and $5 \% \mathrm{CO}_{2}$ at $37^{\circ} \mathrm{C}$ atmosphere. For EMT experiments, cells were treated with $5 \mathrm{ng} / \mathrm{ml}$ TGF- $\beta 1$
(Peprotech, Inc., Rocky Hill, NJ, USA) for 48 h (21). ART (>98\% purity; molecular weight, 384.43) was purchased from TCI (Shanghai) Development Co., Ltd. (Shanghai, China). In order to determine the effect of ART on the activity and proliferation of NRK-52E cells induced by TGF- $\beta 1$, cells were seeded at $60-70 \%$ confluence in complete medium containing $10 \%$ FBS for $24 \mathrm{~h}$, and subsequently serum-starved for $12 \mathrm{~h}$. The cells were subsequently induced with TGF- $\beta 1(5 \mathrm{ng} / \mathrm{ml})$, treated with different ART concentrations (0, 0.01, 0.1 and $1 \mu \mathrm{g} / \mathrm{ml}$ ) containing $1 \% \mathrm{FBS}$ and incubated for $48 \mathrm{~h}$. The groups for the experiment were as follows: Control group, TGF- $\beta 1$ group (normal NRK-52E cells treated with $5 \mathrm{ng} / \mathrm{ml}$ TGF- $\beta 1)$, ART-L group $(0.01 \mu \mathrm{g} / \mathrm{ml}$ ART), ART-M group $(0.1 \mu \mathrm{g} / \mathrm{ml} \mathrm{ART})$, and ART-H group (1 $\mu \mathrm{g} / \mathrm{ml} \mathrm{ART})$. Cells were harvested, following which the expression of associated proteins and genes was determined.

MTT assay for cell viability. NRK-52E cells were seeded into 96-well culture plates and treated with various ART concentrations $(0,0.01,0.11,5$ and $10 \mu \mathrm{g} / \mathrm{ml})$ for $48 \mathrm{~h}$. Cell viability was determined via an MTT assay and cells were incubated with $20 \mu \mathrm{l} \mathrm{MTT}$ solution $(0.5 \mathrm{mg} / \mathrm{ml})$ for $4 \mathrm{~h}$ at $37^{\circ} \mathrm{C}$. The purple formazan crystals derived from the MTT were dissolved in $150 \mu \mathrm{l}$ dimethyl sulfoxide and agitated for $10 \mathrm{~min}$. The absorbance at $490 \mathrm{~nm}$ was measured with a microplate reader (Elx808; BioTek Instruments, Inc., Winooski, VT, USA).

Morpholopy observation. After treatment with TGF- $\beta 1$ combined with or without ART for $48 \mathrm{~h}$, cells were washed with PBS twice. The morphological changes of NRK-52E cells were observed under a phase-contrast photomicroscope (Leica Microsystems GmbH, Wetzlar, Germany) and photographed using a digital camera.

Reverse transcription (RT)-sqPCR analysis. Total RNA was extracted using TRIzol reagent (Tiangen Biotech Co., Ltd.), according to manufacturer's instructions, and the cDNA was synthesized using a TIANScript RT kit (Tiangen Biotech Co., Ltd.) (22). Primers were synthesized by Sangon Biotech Co., Ltd. (Shanghai, China). sqPCR was performed as previously described (22). The sequences of the primers used were as follows: $\alpha$-SMA forward, 5'-GCATCCACG AAACCACCT-3' and reverse, 5'-CGCCGATCCAGACAG AAT-3' (210 bp); E-cadherin forward, 5'-TTCAACCCAAGC ACGTACCA-3' and reverse, 5'-CAGAATGCCCTCGTT GGTCT-3' (186 bp); BMP-7 forward, 5'-GCACCTCCAGGG AAAAC-3' and reverse, 5'-AAGCCCAGATGGTACGG-3' (443 bp); USAG-1 forward, 5'-AGATTTGATTGCGTGGAA GAC-3' and reverse, 5'-GGTTCGGAGGGATTTAGTTTG-3' (311 bp); collagen type I (Col I) forward, 5'-TCAGGGGCG AAGGCAACAGT-3' and reverse, TTGGGATGGAGGGAG TTTACACGA-3' (219 bp); and GAPDH forward, 5'-TGC TGAGTATGTCGTGGAGT-3' and reverse, 5'-AGTCTT CTGAGTGGCAGTGAT-3' (289 bp). PCR amplification was performed with initial denaturation at $94^{\circ} \mathrm{C}$ for $5 \mathrm{~min}$, followed by 30 consecutive cycles of denaturation at $94^{\circ} \mathrm{C}$ for $30 \mathrm{sec}$, annealing at $58-62^{\circ} \mathrm{C}$ for $30 \mathrm{sec}$ and extension at $72^{\circ} \mathrm{C}$ for $1 \mathrm{~min}$, with a final extension at $72^{\circ} \mathrm{C}$ for $7 \mathrm{~min}$. The amplified products were analyzed by electrophoresis on a $1.5 \%$ $(\mathrm{w} / \mathrm{v})$ agarose gel and stained with fluorescence staining dye 
Goldview (Beijing Solarbio Science and Technology Co., Ltd.) alongside a DNA marker (Tiangen Biotech Co., Ltd.) The relative mRNA levels of various genes were calculated following normalization to GAPDH. The signal intensity of the images was analyzed using ImageJ version 1.48 software (National Institutes of Health, Bethesda, MD, USA).

Western blot analysis. Cells were lysed with radioimmunoprecipitation assay buffer (Beyotime Institute of Biotechnology), supplemented with phenylmethylsulfonyl fluoride. The protein samples were quantified using bicinchoninic acid protein assay reagents (Beyotime Institute of Biotechnology). Western blot analysis was performed as previously described (23). Following boiling for $10 \mathrm{~min}$ in a $5 \mathrm{X}$ loading buffer (Beyotime Institute of Biotechnology), protein samples $(45 \mu \mathrm{g})$ were separated by SDS-PAGE on an $8 \%$ gel and transferred onto nitrocellulose membranes (EMD Millipore, Billerica, MA, USA). The membranes were subsequently blocked in PBS containing 3\% BSA (Sigma-Aldrich; Merck KGaA, Darmstadt, Germany) and incubated with primary antibodies at a 1:1,000 dilution overnight at $4^{\circ} \mathrm{C}$. The primary antibodies used were as follows: Anti- $\alpha$-SMA, anti-E-cadherin, anti-BMP-7 and anti-USAG-1. Following washing with PBS-Tween-20, the membrane was incubated with alkaline phosphatase-conjugated goat anti-rabbit and horse anti-mouse secondary antibodies at a 1:1,000 dilution at room temperature for $2 \mathrm{~h}$. Signal detection was performed using an enhanced chemiluminescence kit (Shanghai Tianneng Technology Co., Ltd., Shanghai, China). The band density was measured using ImageJ software.

Immunofluorescent staining. The expressions of E-cadherin, $\alpha$-SMA, BMP-7 and USAG-1 in NRK-52E cells were analyzed by immunofluorescence staining. Cells $\left(2 \times 10^{4}\right.$ cells $\left./ \mathrm{ml}\right)$ were cultured on glass coverslips and treated with TGF- $\beta 1$ with or without $1 \mu \mathrm{g} / \mathrm{ml} \mathrm{ART} \mathrm{for} 48 \mathrm{~h}$. Following treatment for $48 \mathrm{~h}$, cells in the basement layer were washed three times with PBS and fixed in $4 \%$ paraformaldehyde for $15 \mathrm{~min}$ at room temperature. Following three extensive washes with PBS, the cells were treated with $0.5 \%$ Triton $\mathrm{X}-100$ for $10 \mathrm{~min}$ and blocked with $2 \%$ normal donkey serum (Sigma-Aldrich; Merck KGaA) for $1 \mathrm{~h}$ at room temperature, and subsequently incubated with primary antibodies (1:200) at $4^{\circ} \mathrm{C}$ overnight. Cells were washed with PBS for 3-5 min and incubated with goat anti-rabbit and rabbit anti-goat secondary antibodies (Zhongshan Jinqiao Biotechnology Co., Ltd., Beijing, China) at a dilution of 1:200 for $2 \mathrm{~h}$. Following washing in PBS, cells were stained with DAPI (Beyotime Institute of Biotechnology) at room temperature to visualize the nuclei. Following washing in PBS, the device was mounted with anti-fluorescence quenching agent (Beyotime Institute of Biotechnology) and cover-slipped; digital images were captured using an inverted fluorescent microscope (magnification, $\mathrm{x} 400$ ).

Statistical analysis. All data were reported as the mean \pm standard deviation. Statistical analysis was performed using the statistical package SPSS for Windows, version 13.0 (SPSS, Inc., Chicago, IL, USA) and GraphPad Prism v. 5.0 (GraphPad Software, Inc., La Jolla, CA, USA). The comparisons among different groups were made using one-way analysis of variance followed by least significant

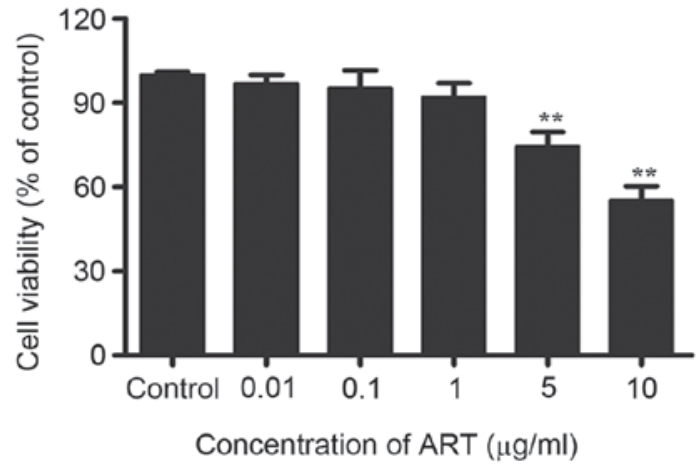

Figure 1. Effect of ART on the cell viability of NRK-52E. NRK-52E cells were incubated with different concentrations of ART for $48 \mathrm{~h}$. All data are presented as the mean \pm standard deviation. $\mathrm{n}=3$. $^{* *} \mathrm{P}<0.01$ vs. control. ART, artesunate.

difference/Dunett-T3 tests. $\mathrm{P}<0.05$ was considered to indicate a statistically significant difference. All experiments were repeated $\geq 3$ times.

\section{Results}

Effect of TGF- $\beta 1$ on NRK-52E cells. In order to investigate the effect of TGF- $\beta 1$ on NRK-52E cells, cells were treated with different concentrations of TGF- $\beta 1(2,5$ and $10 \mu \mathrm{g} / \mathrm{ml})$ for $48 \mathrm{~h}$. The results demonstrated that 5 and $10 \mu \mathrm{g} / \mathrm{ml}$ TGF- $\beta 1$ was able to significantly increase the expression of $\alpha$-SMA mRNA and protein. In addition, TGF- $\beta 1$ (5 and $10 \mu \mathrm{g} / \mathrm{ml})$ was able to downregulate the expression of E-cadherin mRNA, while a concentration of $2 \mu \mathrm{g} / \mathrm{ml}$ TGF- $\beta 1$ had no significant effect on $\alpha$-SMA mRNA and protein and E-cadherin mRNA compared with the control group. Additionally, TGF- $\beta 1$ was able to decrease cell-cell contact and the cells adopted a more elongated morphology at a concentration of $5 \mathrm{ng} / \mathrm{ml}$. However, TGF- $\beta 1$ did not influence cell morphology at a concentration of $2 \mathrm{ng} / \mathrm{ml}$. Therefore, $5 \mathrm{ng} / \mathrm{ml}$ TGF- $\beta 1$ was selected as the concentration to be used in the following experiment (data not shown). Subsequently, NRK-52E cells were treated with $5 \mathrm{ng} / \mathrm{ml}$ TGF- $\beta 1$ for 24, 48 and $72 \mathrm{~h}$, and the results demonstrated that the expression of $\alpha$-SMA mRNA was significantly upregulated compared with the control group when treated for $48 \mathrm{~h}$, while TGF- $\beta 1$ had no marked effect on $\alpha$-SMA mRNA expression when cells were treated for $24 \mathrm{~h}$. In addition, the cellular morphology gradually altered from oval to a long spindle shape over time, and this alteration was apparent at $48 \mathrm{~h}$; however, cellular morphology was almost unaltered compared with the control group at $24 \mathrm{~h}$ (data not shown). According to the above results, $5 \mathrm{ng} / \mathrm{ml}$ TGF- $\beta 1$ for $48 \mathrm{~h}$ was selected as the treatment to be used for the remainder of the experiments.

Effect of ART on cellular viability. In order to determine the effect of ART on cell viability, NRK-52E cells $\left(2.5 \times 10^{4}\right.$ cells $\left./ \mathrm{ml}\right)$ were seeded into 96 -well culture plates and treated with different concentrations of ART (0.01, 0.1, 1,5 and $10 \mu \mathrm{g} / \mathrm{ml}$ ) for $48 \mathrm{~h}$, following which cell viability was determined. The results demonstrated that there was little or no effect on cell viability low-doses of ART $(0.01,0.1$ and 
A

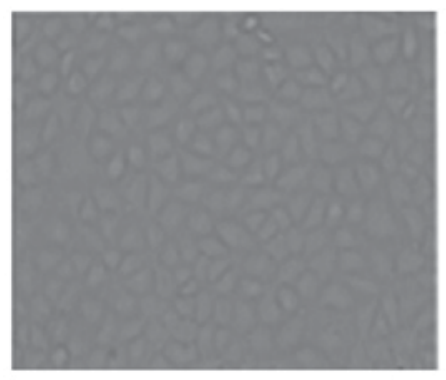

D

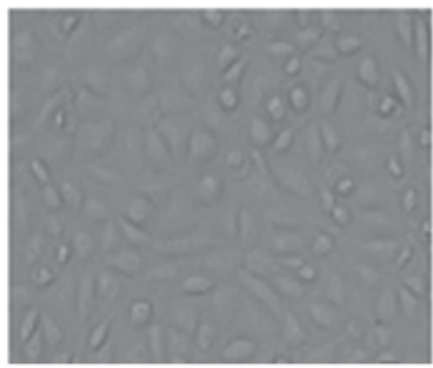

B

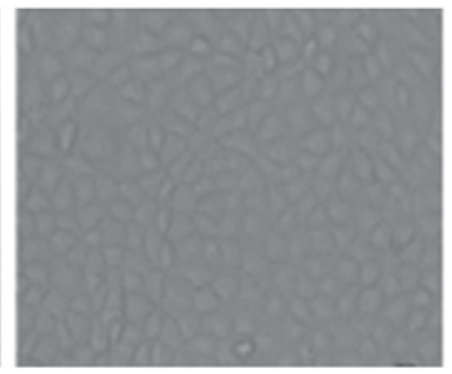

$\mathrm{E}$

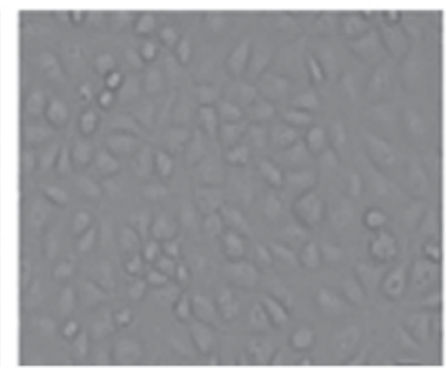

C

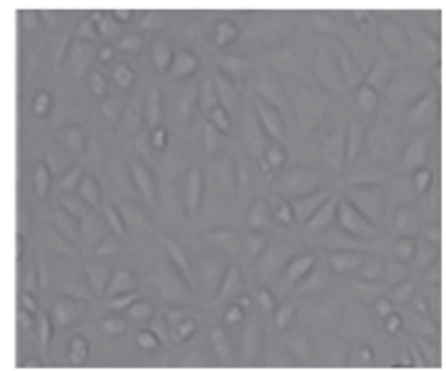

$\mathrm{F}$

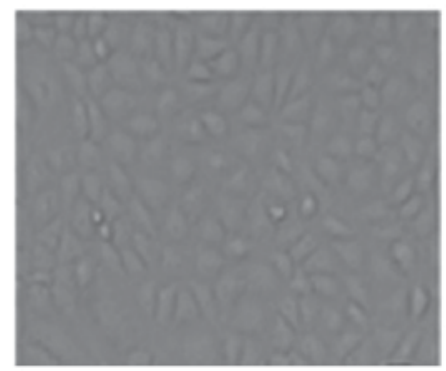

Figure 2. Effect of ART on the morphology of NRK-52E cells. Incubation of NRK-52E cells with different concentrations of ART with or without transforming growth factor- $\beta 1$ for 48 h. Representative images are presented: (A) Control group; (B) ART group; (C) TGF- $\beta 1$ group; (D) ART low dose group; (E) ART moderate dose group; (F) ART high dose group. Magnification, x100. ART, artesunate.

$1 \mu \mathrm{g} / \mathrm{ml})$. However, treatment with 5 or $10 \mu \mathrm{g} / \mathrm{ml}$ ART resulted in a significant decrease in cell viability (Fig. 1). Therefore, $0.01,0.1$ and $1 \mu \mathrm{g} / \mathrm{ml}$ were used for the following experiments.

Effect of ART on cell morphology. In order to observe the alterations in cellular morphology caused by treatment with ART, the morphological alterations in NRK-52E cells were observed under a phase-contrast photomicroscope (Leica Microsystems $\mathrm{GmbH}$ ) and photographed using a digital camera. The control cells exhibited a typical epithelial cuboidal shape with cobblestone morphology (Fig. 2A). Treatment with ART alone (ART group) had no effect on morphology compared with the control group (Fig. 2B); therefore, this group was not included in the following experiment. By contrast, NRK-52E cells exposed to TGF- $\beta 1$ ( $5 \mathrm{ng} / \mathrm{ml})$ exhibited a decrease in cell-cell contacts and adopted a more elongated morphological shape. Notably, treatment with TGF- $\beta 1$ resulted in a morphology which was fibroblast-like in nature and identifiable by the presence of elongated lamellipodia and a spindle shape, as presented in Fig. 2C. However, ART was able to improve the morphology of cells to different degrees and a dose of ART at $1 \mu \mathrm{g} / \mathrm{ml}$ rendered the cellular morphology close to the normal cellular morphology (Fig. 2D-F). These results indicated that ART was able to improve TGF- $\beta 1$-induced morphological alterations in cells.

Effects of ART on the levels of E-cadherin, $\alpha$-SMA and Col I in NRK-52E cells. In order to evaluate the regulatory effects of ART in TGF- $\beta 1$-induced EMT, the expression of E-cadherin and $\alpha$-SMA was examined at the mRNA and protein levels in epithelial cells. The level of $\alpha$-SMA expression was low, while E-cadherin expression was high in normal renal tubular epithelial cells. The results suggested that TGF- $\beta 1$-induced cells exhibited a significant decrease in the gene expression of E-cadherin (Fig. 3A; P<0.01), and ART-L had no significant effect on the expression of E-cadherin. The expression of E-cadherin was significantly increased in the ART-M and ART-H groups, particularly at the highest concentration of ART (Fig. 3A). The mRNA expression of $\alpha$-SMA in TGF- $\beta 1$-induced EMT was significantly upregulated compared with the control group. Treatment with ART significantly attenuated the TGF- $\beta 1$-induced increase in the mRNA expression of $\alpha$-SMA, and this was more apparent at moderate and high doses of ART (Fig. 3B). These results confirmed that EMT served a role in tubulointerstitial fibrosis, and that ART may improve renal fibrosis by inhibiting the process of EMT. The occurrence of EMT ultimately leads to deposition of the ECM, and Col I is the ECM deposit which results from EMT occurrence. To evaluate the regulatory effects of ART in TGF- $\beta 1$-induced ECM protein accumulation, the mRNA expression of Col I was examined. The results demonstrated that the expression of Col I was increased in cells undergoing EMT, which was pathologically associated with fibrosis, while treatment with ART in the low concentration group decreased the level of Col I and the difference was statistically significant with moderate and high concentrations of ART (Fig. 3C). The results demonstrated that the ECM was significantly accumulated in renal fibrosis, and that ART was able to decrease the accumulation of the ECM.

The expression of E-cadherin and $\alpha$-SMA protein was examined in total cell lysates using western blotting. The results demonstrated that TGF- $\beta 1$ was able to increase the expression of $\alpha$-SMA and decrease the E-cadherin expression in NRK-52E cells, demonstrating that TGF- $\beta 1$ stimulated EMT in tubular cells, which is consistent with previous reports (6). However, treatment with ART significantly 

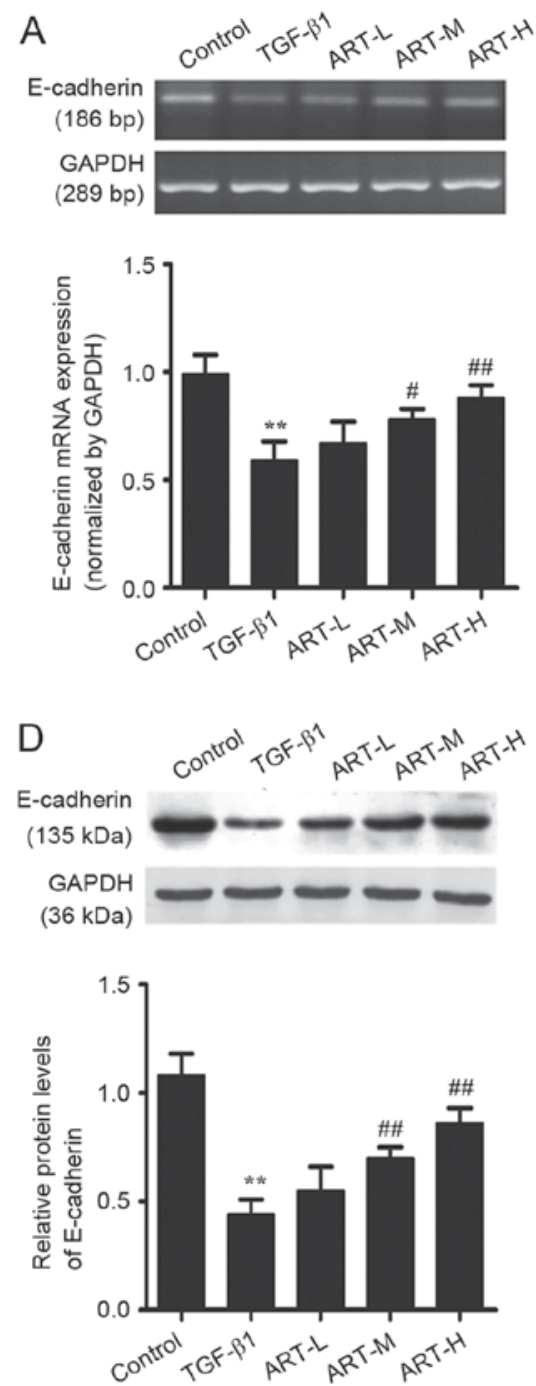

B
$\alpha$-SMA
$(210 \mathrm{bp})$

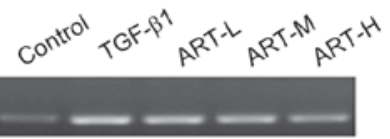

GAPDH

(289 bp)
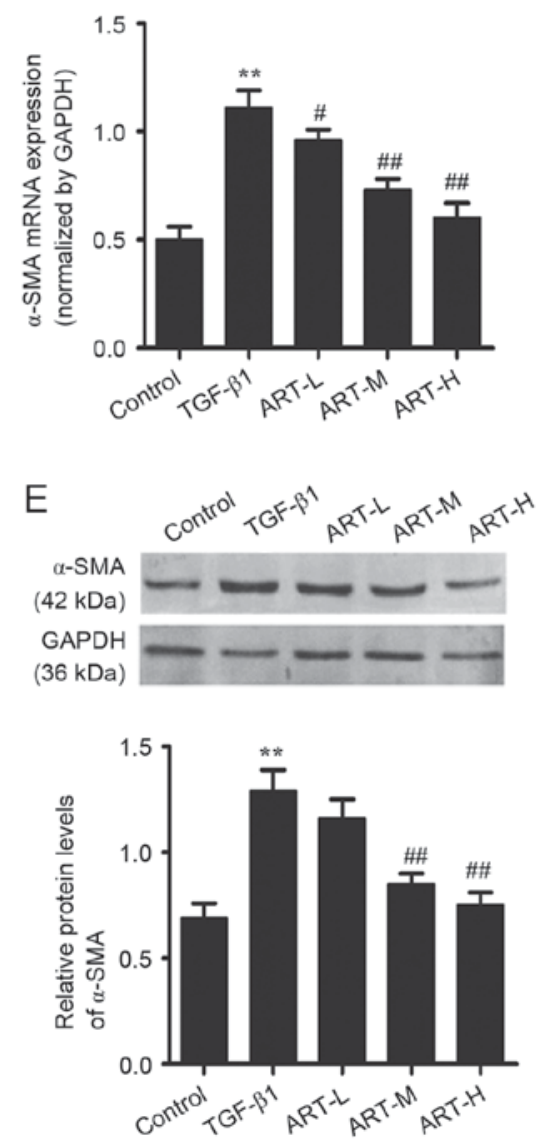
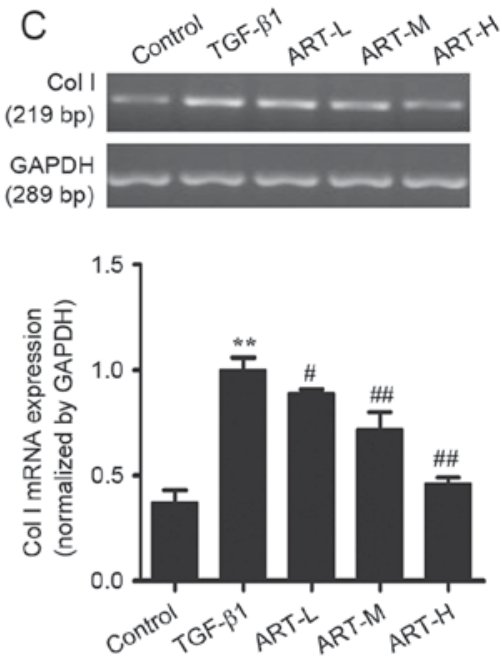

Figure 3. Effect of ART on the expression of E-cadherin, $\alpha$-SMA and Col I at the mRNA and protein levels in NRK-52E cells. Incubation of NRK-52E cells with different concentrations of ART with or without TGF- $\beta 1$ for $48 \mathrm{~h}$. Reverse transcription-semi-quantitative polymerase chain reaction analysis was used to detect the expression of (A) E-cadherin, (B) $\alpha$-SMA and (C) Col I mRNA. Western blotting was applied to examine the protein levels of (D) E-cadherin and (E) $\alpha$-SMA. GAPDH was used as the internal loading control. All data are presented as the mean \pm standard deviation. $n=3{ }^{* *} \mathrm{P}<0.01 \mathrm{vs}$. control; ${ }^{\#} \mathrm{P}<0.05$, ${ }^{\# \#} \mathrm{P}<0.01$ vs. TGF- $\beta 1$. ART, artesunate; ART-L, low-dose ART; ART-M, moderate-dose ART; ART-H, high-dose ART; $\alpha$-SMA, $\alpha$-smooth muscle actin; Col I, collagen type I; TGF- $\beta 1$, transforming growth factor- $\beta 1$.

increased E-cadherin expression and downregulated $\alpha$-SMA protein expression, which is in line with previous findings in the UUO model (20). In addition, the effect was more marked at moderate and high doses of ART (Fig. 3D and E).

The involvement of $\alpha$-SMA and E-cadherin in TGF- $\beta 1$-induced EMT was further investigated via a fluorescence confocal assay. Under basal condition, the expression of E-cadherin was abundant in renal tubular epithelial cells, and was primarily localized to the plasma membrane (Fig. 4A). When the renal tubular cells were stimulated by TGF- $\beta 1$, the expression of E-cadherin was markedly decreased, as exhibited by decreased green fluorescence; when cells were pretreated with ART, the TGF- $\beta 1$-induced E-cadherin delocalization was inhibited (Fig. 4A). By contrast, the abundance of the mesenchymal marker $\alpha$-SMA was low in renal tubular cells under control conditions, as indicated by the weak fluorescence in confocal images (Fig. 4B). When the cells were stimulated by TGF- $\beta 1$, the expression of $\alpha$-SMA was markedly increased, as exhibited by the increased fluorescence in the confocal images (Fig. 4B). When renal tubular cells were pretreated with ART, TGF- $\beta 1$ failed to increase $\alpha$-SMA expression (Fig. 4B). These results further confirmed that ART may improve TGF- $\beta 1$-induced EMT progression.

Effect of ART on the expression of USAG-1 and BMP-7 at the $m R N A$ and protein levels in NRK-52E cells. TGF- $\beta 1$ is considered to be an important cytokine for the induction of renal interstitial fibrosis, and BMP-7 is a member of the TGF- $\beta 1$ superfamily. A previous study reported that BMP-7 may be able to reverse the renal structural alterations and the degree of fibrosis in UUO rats by regulating the downstream mothers against decapentaplegic homolog (Smad)1/5/8 signaling pathway (24). USAG-1 serves as the endogenous antagonist of BMP-7. Therefore, the present study examined the expression of USAG-1 and BMP-7, and the underlying mechanism.

In order to determine the regulatory effects of ART in TGF- $\beta 1$-induced BMP-7 and USAG-1 expression, RT-sqPCR analysis and western blotting were performed (Fig. 5). TGF- $\beta 1$ 
A

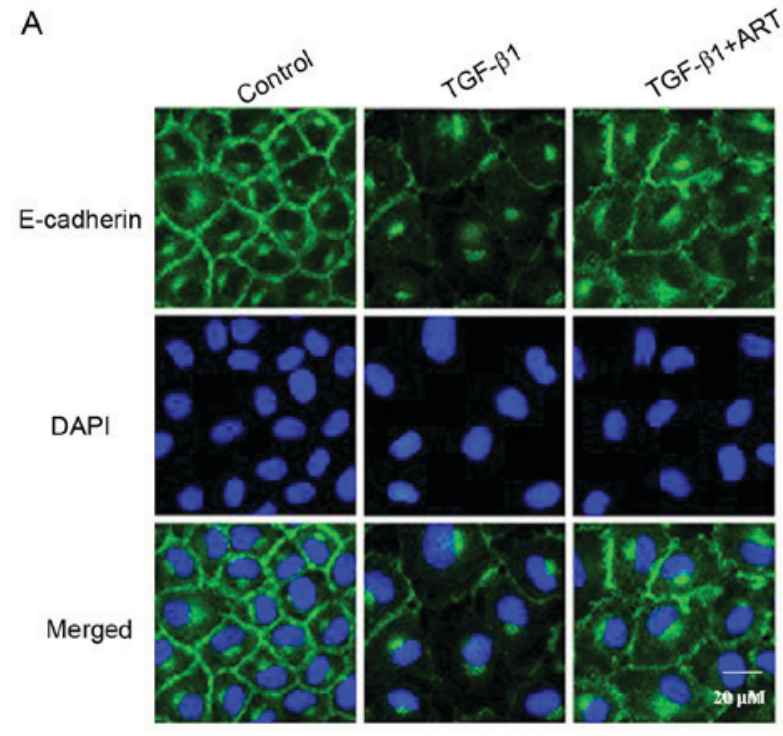

B
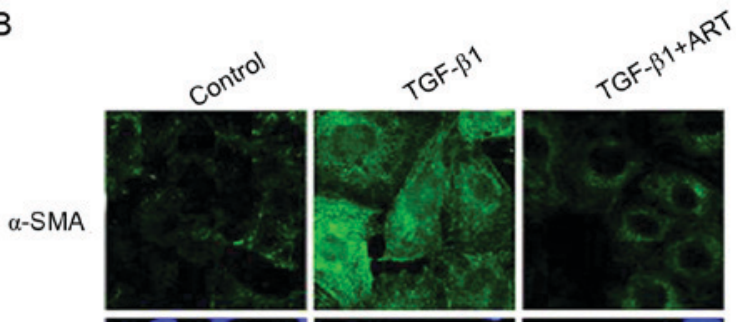

DAPI
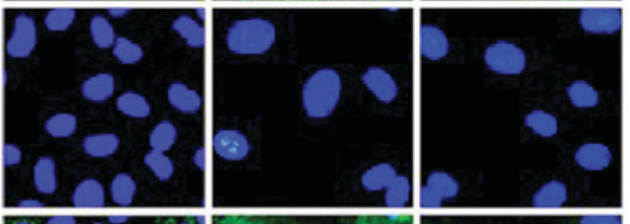

Merged
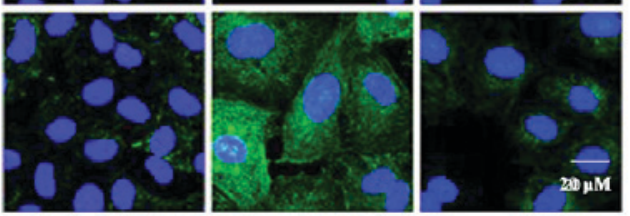

Figure 4. Immunofluorescence staining was performed to determine the expression of (A) E-cadherin and (B) $\alpha$-SMA. Magnification, $\mathrm{x} 400 . \alpha-S M A, \alpha$-smooth muscle actin; TGF- $\beta 1$, transforming growth factor- $\beta 1$; ART, artesunate.
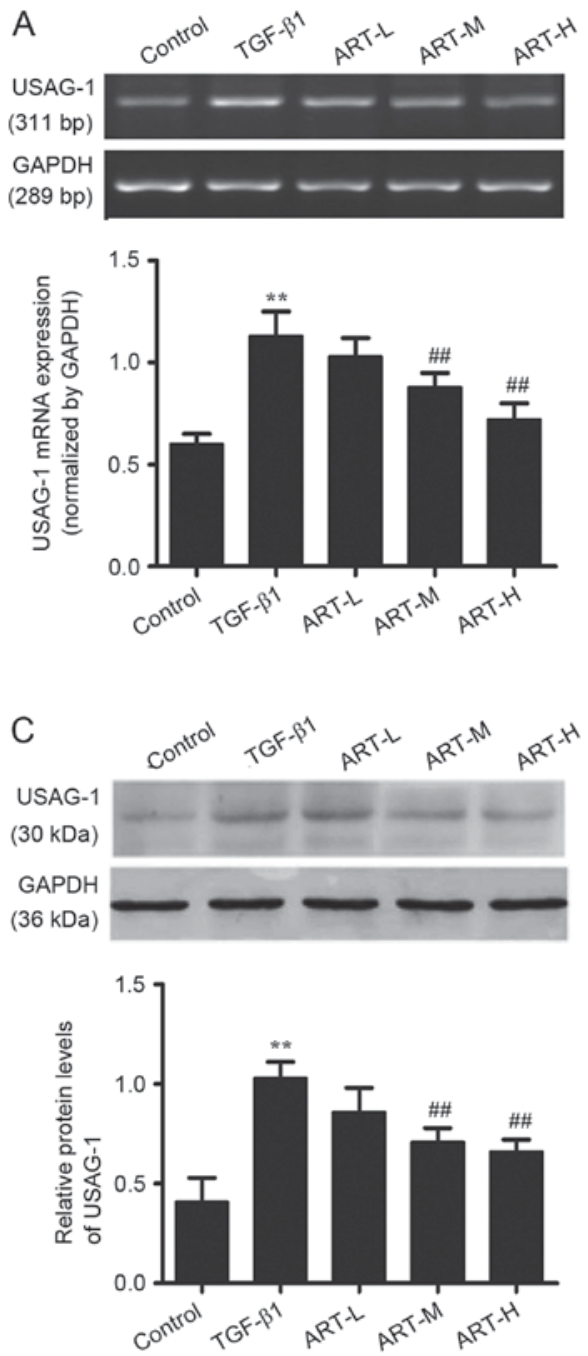
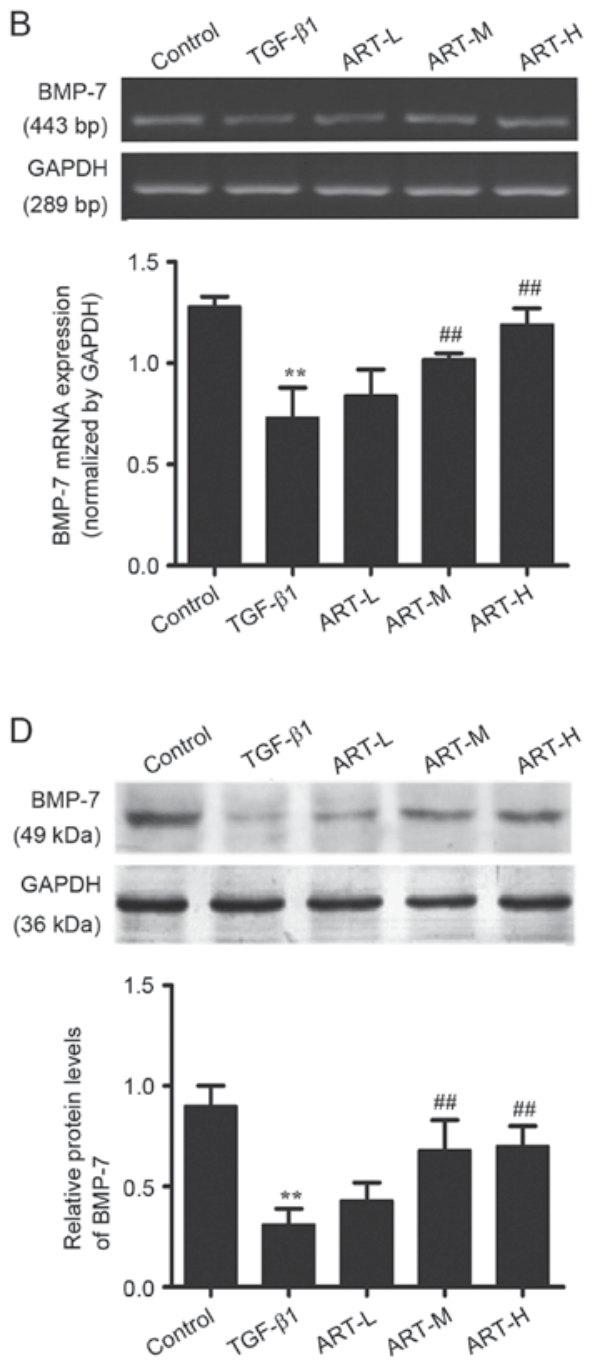

Figure 5. Effect of ART on the expression of USAG-1 and BMP-7 at the mRNA and protein levels in NRK-52E cells. NRK-52E cells were incubated with different concentrations of ART, with or without TGF- $\beta 1$, for $48 \mathrm{~h}$. Reverse transcription-semi-quantitative polymerase chain reaction analysis was used to detect the expression of (A) USAG-1 and (B) BMP-7 mRNA. Western blotting was applied to examine the protein levels of (C) USAG-1 and (D) BMP-7. GAPDH was used as the internal loading control. All data are presented as the mean \pm standard deviation. $\mathrm{n}=3$. ${ }^{* *} \mathrm{P}<0.01 \mathrm{vs}$. control; ${ }^{\# \#} \mathrm{P}<0.01 \mathrm{vs}$. TGF- $\beta 1$. ART, artesunate; ART-L, low-dose ART; ART-M, moderate-dose ART; ART-H, high-dose ART; TGF- $\beta 1$, transforming growth factor- $\beta 1$; USAG- 1 , uterine sensitization-associated gene 1; BMP-7, bone morphogenetic protein 7. 
A

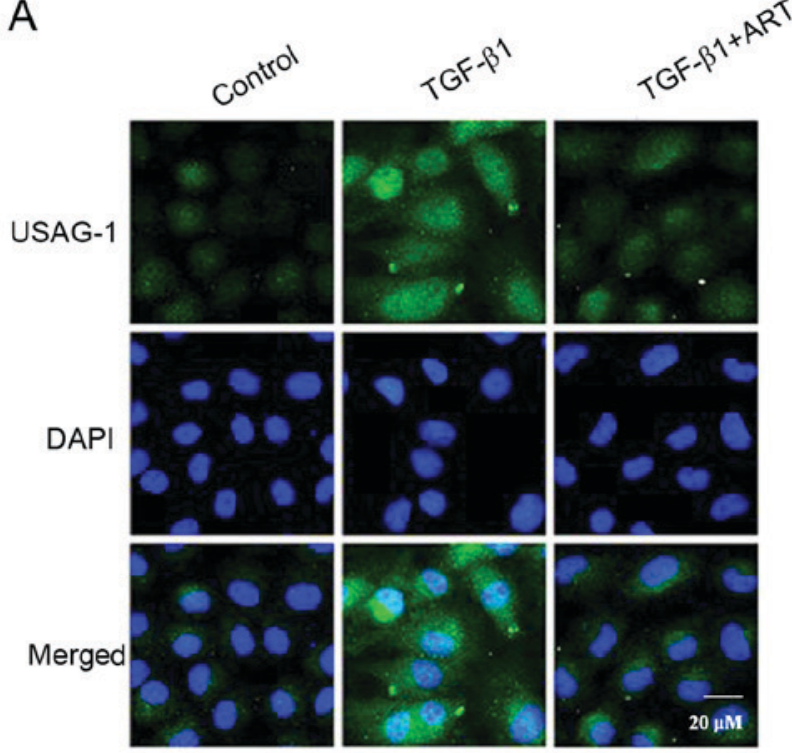

$B$

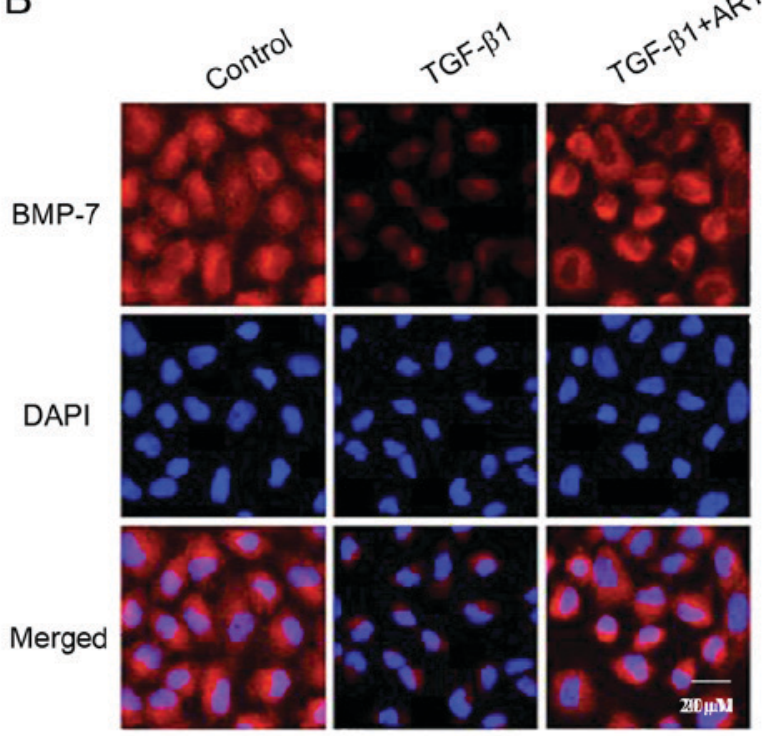

Figure 6. Immunofluorescence staining was performed to determine the expression of (A) USAG-1 and (B) BMP-7. Magnification, $\mathrm{x} 400$. TGF- $\beta 1$, transforming growth factor- $\beta 1$; ART, artesunate; USAG-1, uterine sensitization-associated gene 1; BMP-7, bone morphogenetic protein 7.

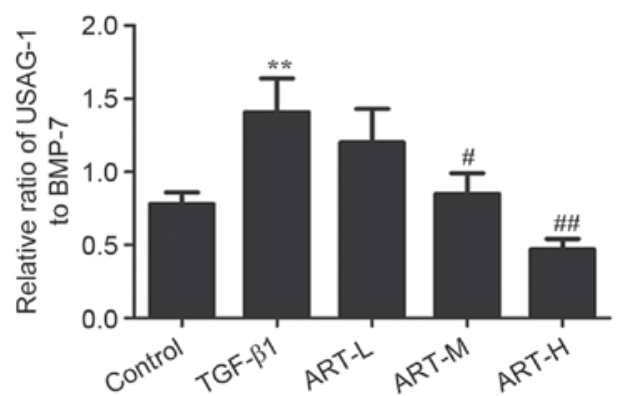

Figure 7. Effects of ART on the protein ratio of USAG-1 to BMP-7. Data are presented as the mean \pm standard deviation. $\mathrm{n}=3$. $^{* *} \mathrm{P}<0.01$ vs. control; ${ }^{\#} \mathrm{P}<0.05,{ }^{\#} \mathrm{P}<0.01$ vs. TGF- $\beta 1$. ART, artesunate; ART-L, low-dose ART; ART-M, moderate-dose ART; ART-H, high-dose ART; TGF- $\beta 1$, transforming growth factor- $\beta 1$; USAG-1, uterine sensitization-associated gene 1 ; BMP-7, bone morphogenetic protein 7 .

upregulated the expression of USAG-1 in NRK-52E cells as presented in Fig. 5A and C. Treatment with ART (0.1 and $1 \mu \mathrm{g} / \mathrm{ml})$ significantly decreased the expression of USAG-1 in a dose-dependent manner compared with the TGF- $\beta 1$ treated group (Fig. 5A and C). The effect of ART on the expression of BMP-7 was additionally detected. Compared with the control group, the expression of BMP-7 significantly decreased when treated with TGF- $\beta 1$; however, ART was able to restore the expression of BMP-7, and the highest dose of ART exerted the most marked effect (Fig. 5B and D). The results of the RT-sqPCR analysis of USAG-1 and BMP-7 were consistent with those of the western blot analysis.

In order to observe the localization of BMP-7 and USAG-1 in NRK-52E cells, immunofluorescent staining was performed to detect the two proteins (Fig. 6). The results demonstrated that the expression of USAG-1 in NRK-52E cells was minimal, while the expression of USAG-1 was markedly increased when treated with $5 \mathrm{ng} / \mathrm{ml}$ TGF- $\beta 1$. Notably, ART inhibited the increased expression of USAG-1 (Fig. 6A). Additionally, BMP-7 was abundantly expressed in NRK-52E cells; however, the expression of BMP-7 was significantly decreased when induced by TGF- $\beta 1$, and ART was able to reverse this effect (Fig. 6B). The results further clarified that the expression of BMP-7 and USAG-1 may alter when induced by TGF- $\beta 1$, and suggested that ART may reverse these effects.

Effect of ART on the ratio of USAG-1 to BMP-7. In order to demonstrate the role of BMP-7 and USAG-1 in EMT, the effects of ART on the protein ratio of USAG-1 to BMP-7 were evaluated following treatment with TGF- $\beta 1$. The ratio increased in the TGF- $\beta 1$ group compared with the control group (Fig. 7). However, the three doses of ART in the experiment inhibited the elevation of the ratio, and this was significant in the ART-H and ART-M groups, demonstrating that the ameliorative effect of ART in EMT may be achieved by restoring the ratio of USAG-1 and BMP-7.

\section{Discussion}

The primary aim of the present study was to investigate the role of ART in EMT induced by TGF- $\beta 1$. In the present study, 2 days of exposure to TGF- $\beta 1$ in renal proximal tubular cells significantly increased the levels of $\alpha$-SMA and decreased the expression of E-cadherin, suggesting that TGF- $\beta 1$ was able to induce the occurrence of EMT (25). In addition, it was demonstrated that ART was able to ameliorate TGF- $\beta 1$-induced renal interstitial fibrosis. Notably, ART reversed the TGF- $\beta$-induced increase in USAG-1 and decrease in BMP-7. The downregulation of USAG-1 expression resulted in the inhibition of EMT. These results provided evidence for a possible antifibrotic mechanism in renal interstitial fibrosis.

Renal interstitial fibrosis, which is characterized by the accumulation of the ECM, is the principal underlying pathology in the progression of chronic kidney diseases, and is a common pathway of chronic kidney disease progression to end-stage renal failure (1). The pathogenesis of renal fibrosis is characterized by tubular atrophy, tubular cell loss, 
myofibroblast accumulation and excessive ECM protein deposition (26). EMT is a process through which epithelial cells lose their epithelial-specific biomarkers, undergo cytoskeletal remodeling, and gain a mesenchymal phenotype (4). It has been reported that the TGF- $\beta$-Smad signaling pathway may promote the occurrence of EMT. Studies have demonstrated that tubular EMT is an important resource of fibrogenic myofibroblasts and serves a central role in tubulointerstitial fibrosis, including in diabetes nephropathy. In the present study, ART-treated cells displayed a significant decrease in the levels of $\alpha$-SMA and an increase the expression of E-cadherin, and ART was able to improve the morphological alterations induced by TGF- $\beta 1$ and restore the morphology of the epithelial cells; these results indicated that ART may improve renal fibrosis induced by TGF- $\beta 1$. Additionally, ART reversed the process of EMT induced by TGF- $\beta 1$.

BMP-7, a morphogenetic protein, has been hypothesized to serve a role in antifibrosis in renal tubular epithelial cells (27). Under normal circumstances, there is abundant BMP-7 expression in renal tubular epithelial cells, and BMP-7 is able to maintain the normal functioning of renal tubular epithelial cells (28). The expression of BMP-7 has been demonstrated to be significantly downregulated under disease conditions, including hypertension, aristolochic acid nephropathy, diabetic nephropathy and other disease states $(29,30)$. In addition, it was reported that exogenous administration of recombinant human BMP-7 was able to reverse the alterations in renal structure and the degree of fibrosis in UUO rats by regulating the downstream Smad1/5/8 signaling pathway (24). A previous study demonstrated that BMP-7 inhibited TGF- $\beta 1$-induced fibrogenesis and EMT, and induced EMT in vitro (31). In the present study, the levels of BMP-7 mRNA and protein levels decreased during the process of EMT, which was further confirmed by the immunofluorescent staining results. However, ART was able to inhibit the process of EMT and significantly increase the levels of BMP-7, indicating that ART may inhibit the EMT process via an upregulation of BMP-7 expression.

It has been demonstrated that the local activity of endogenous BMP-7 is controlled by the regulation of its expression, in addition to certain classes of molecules termed BMP antagonists (13). USAG-1, a dominant antagonist of BMP-7, is primarily expressed in renal tubular epithelial cells and contributes to renal injury $(9,10)$. In previous studies, it was demonstrated that USAG-1-knockout mice exhibited reduced tubulointerstitial fibrosis in a UUO model, and improved renal function in acute and chronic kidney injury. The above results illustrated that the upregulation of USAG-1 may serve an important role in the process of renal interstitial fibrosis (12). In the present study, the expression of USAG-1 was upregulated when induced by TGF- $\beta 1$, although it significantly decreased when treated with ART, particularly the high dose of ART. In addition, the reduction of USAG-1 expression may improve other indicators of fibrosis. The results stated above suggested that one of the possible mechanisms underlying the antifibrotic effects of ART may be associated with inhibition of the expression of USAG-1 in NRK-52E cells.

In conclusion, the results above demonstrate that ART was able to inhibit EMT induced by TGF- $\beta 1$. These effects may be associated with the upregulation of BMP-7 or the inhibition of
USAG-1 expression, although the exact mechanisms require further investigation.

\section{Acknowledgements}

The present study were funded by grants from the Jiangsu Key Laboratory of New Drug Research and Clinical Pharmacy (grant no. ZR-XY201408), and the College of Pharmacy, Xuzhou Medical University (grant no. 2015YKYCX009).

\section{References}

1. Boor P, Ostendorf T and Floege J: Renal fibrosis: Novel insights into mechanisms and therapeutic targets. Nat Rev Nephrol 6: 643-656, 2010.

2. Jepson RE: Current understanding of the pathogenesis of progressive chronic kidney disease in cats. Vet Clin North Am Small Anim Pract 46: 1015-1048, 2016.

3. Liu Y: Cellular and molecular mechanisms of renal fibrosis. Nat Rev Nephrol 7: 684-696, 2011.

4. Barnes JL and Glass WF II: Renal interstitial fibrosis: A critical evaluation of the origin of myofibroblasts. Contrib Nephrol 169: 73-93, 2011.

5. Akhurst RJ and Padgett RW: Matters of context guide future research in TGF $\beta$ superfamily signaling. Sci Signal 8: re10, 2015.

6. Liu Y: New insights into epithelial-mesenchymal transition in kidney fibrosis. J Am Soc Nephrol 21: 212-222, 2010.

7. Meng XM, Chung AC and Lan HY: Role of the TGF- $\beta$ /BMP-7/Smad pathways in renal diseases. Clin Sci (Lond) 124: 243-254, 2013.

8. Liang D, Wang Y, Zhu Z, Yang G, An G, Li X, Niu P, Chen L and Tian L: BMP-7 attenuated silica-induced pulmonary fibrosis through modulation of the balance between TGF- $\beta /$ Smad and BMP-7/Smad signaling pathway. Chem Biol Interact 243: 72-81, 2016.

9. Yanagita M,OkudaT,EndoS,TanakaM,TakahashiK,SugiyamaF, Kunita S, Takahashi S, Fukatsu A, Yanagisawa M, et al: Uterine sensitization-associated gene-1 (USAG-1), a novel BMP antagonist expressed in the kidney, accelerates tubular injury. J Clin Invest 116: 70-79, 2006.

10. Yanagita M, Oka M, Watabe T, Iguchi H, Niida A, Takahashi S, Akiyama T, Miyazono K, Yanagisawa M and Sakurai T: USAG-1: A bone morphogenetic protein antagonist abundantly expressed in the kidney. Biochem Biophys Res Commun 316: 490-500, 2004.

11. Tanaka M, Endo S, Okuda T, Economides AN, Valenzuela DM, Murphy AJ, Robertson E, Sakurai T, Fukatsu A, Yancopoulos GD, et al: Expression of BMP-7 and USAG-1 (a BMP antagonist) in kidney development and injury. Kidney Int 73: 181-191, 2008.

12. Kiso H, Takahashi K, Saito K, Togo Y, Tsukamoto H, Huang B, Sugai M, Shimizu A, Tabata Y,Economides AN, et al: Interactions between BMP-7 and USAG-1 (uterine sensitization-associated gene-1) regulate supernumerary organ formations. PLoS One 9: e96938, 2014.

13. Nakamura $\mathbf{J}$ and Yanagita $\mathrm{M}$ : Bmp modulators in kidney disease. Discov Med 13: 57-63, 2012.

14. Simmons DG and Kennedy TG: Uterine sensitization-associated gene-1: A novel gene induced within the rat endometrium at the time of uterine receptivity/sensitization for the decidual cell reaction. Biol Reprod 67: 1638-1645, 2002.

15. Collette NM, Yee CS, Murugesh D, Sebastian A, Taher L, Gale NW, Economides AN, Harland RM and Loots GG: Sost and its paralog Sostdcl coordinate digit number in a Gli3-dependent manner. Dev Biol 383: 90-105, 2013.

16. Chong $\mathrm{CM}$ and Zheng W: Artemisinin protects human retinal pigment epithelial cells from hydrogen peroxide-induced oxidative damage through activation of ERK/CREB signaling. Redox Biol 9: 50-56, 2016.

17. Tu Y: The discovery of artemisinin (qinghaosu) and gifts from Chinese medicine. Nat Med 17: 1217-1220, 2011.

18. Wang C, Xuan X, Yao W, Huang G and Jin J: Anti-profibrotic effects of artesunate on bleomycin-induced pulmonary fibrosis in Sprague Dawley rats. Mol Med Rep 12: 1291-1297, 2015. 
19. Lai L, Chen Y, Tian X, Li X, Zhang X, Lei J, Bi Y, Fang B and Song X: Artesunate alleviates hepatic fibrosis induced by multiple pathogenic factors and inflammation through the inhibition of LPS/TLR4/NF- $\kappa$ B signaling pathway in rats. Eur J Pharmacol 765: 234-241, 2015.

20. Cao J, Wang W, Li Y, Xia J, Peng Y, Zhang Y and Xia A Artesunate attenuates unilateral ureteral obstruction-induced renal fibrosis by regulating the expressions of bone morphogenetic protein-7 and uterine sensitization-associated gene- 1 in rats. Int Urol Nephrol 48: 619-629, 2016.

21. Pang M, Wang H, Rao P, Zhao Y, Xie J, Cao Q, Wang Y, Wang YM, Lee VW, Alexander SI, et al: Autophagy links $\beta$-catenin and Smad signaling to promote epithelial-mesenchymal transition via upregulation of integrin linked kinase. Int J Biochem Cell Biol 76: 123-134, 2016.

22. Tanaka T, Doi K, Maeda-Mamiya R, Negishi K, Portilla D, Sugaya T, Fujita T and Noiri E: Urinary L-type fatty acid-binding protein can reflect renal tubulointerstitial injury. Am J Pathol 174 1203-1211, 2009.

23. Meng XM, Huang XR, Chung AC, Qin W, Shao X, Igarashi P $\mathrm{Ju}$ W, Bottinger EP and Lan HY: Smad2 protects against TGF-beta/Smad3-mediated renal fibrosis. J Am Soc Nephrol 21: 1477-1487, 2010.

24. Manson SR, Niederhoff RA, Hruska KA and Austin PF: The BMP-7-Smad1/5/8 pathway promotes kidney repair after obstruction induced renal injury. J Urol 185 (Suppl 6): S2523-S2530, 2011.
25. Lian YG, Zhou QG, Zhang YJ and Zheng FL: VEGF ameliorates tubulointerstitial fibrosis in unilateral ureteral obstruction mice via inhibition of epithelial-mesenchymal transition. Acta Pharmacol Sin 32: 1513-1521, 2011.

26. Lawson JS, Syme HM, Wheeler-Jones CP and Elliott J: Urinary active transforming growth factor $\beta$ in feline chronic kidney disease. Vet J 214: 1-6, 2016.

27. Zeisberg M: Bone morphogenic protein-7 and the kidney: Current concepts and open questions. Nephrol Dial Transplant 21: 568-573, 2006

28. Lim AI, Chan LY, Tang SC, Yiu WH, Li R, Lai KN and Leung JC: BMP-7 represses albumin-induced chemokine synthesis in kidney tubular epithelial cells through destabilization of NF- $\kappa \mathrm{B}$ inducing kinase. Immunol Cell Biol 92: 427-435, 2014.

29. Bramlage CP, Tampe B, Koziolek M, Maatouk I, Bevanda J, Bramlage P, Ahrens K, Lange K, Schmid H, Cohen CD, et al: Bone morphogenetic protein (BMP)-7 expression is decreased in human hypertensive nephrosclerosis. BMC Nephrol 11: 31, 2010.

30. Ivanac-Janković R, Corić M, Furić-Čunko V, Lovičić V, Bašić-Jukić N and Kes P: BMP-7 protein expression is downregulated in human diabetic nephropathy. Acta Clin Croat 54: 164-168, 2015.

31. Zeisberg M, Hanai J, Sugimoto H, Mammoto T, Charytan D, Strutz F and Kalluri R: BMP-7 counteracts TGF-beta1-induced epithelial-to-mesenchymal transition and reverses chronic renal injury. Nat Med 9: 964-968, 2003. 